Verano/Verão 2018

\title{
The Hidden Moral Teleology in Fichte's System of Ethics
}

Kienhow Goh

\section{(2) OpenEdition \\ Journals}

Electronic version

URL: http://journals.openedition.org/ref/929

DOI: $10.4000 /$ ref.929

ISSN: 2258-014X

Publisher

EuroPhilosophie Editions

Electronic reference

Kienhow Goh, "The Hidden Moral Teleology in Fichte's System of Ethics ", Revista de Estud(i)os sobre Fichte [Online], 17 | 2018, Online since 01 December 2018, connection on 08 September 2020. URL : http://journals.openedition.org/ref/929 ; DOI : https://doi.org/10.4000/ref.929

This text was automatically generated on 8 September 2020

(C) EuroPhilosophie 


\title{
The Hidden Moral Teleology in Fichte's System of Ethics
}

\author{
Kienhow Goh
}

1 In Kant's critical system of philosophy, the moral law serves both as a practical command and as a cosmic principle. While its function as a practical command is expounded at length in the branch of philosophy known as the metaphysics of morals, its function as a cosmic principle is only briefly touched upon in the branch of critique known as moral teleology (as a prelude to moral theology). One might expect the principal ethical work written by Fichte during his glorious days in Jena - the System of Ethics (SE) - to be primarily, if not exclusively, concerned with the law as a practical command. On this score, the work turns out to be strikingly exceptional: it investigates the law's function as a cosmic principle with the hope of delivering a deduction of its applicability in the world of sense. In what follows, I argue that Fichte harnesses the concept of the original, determinate end of a natural thing in the deduction as a means of mediating the Kantian "supersensible idea of the morally good" by sensible intuitions. In doing so, he is inspired above all by Kant's moral teleology.

\section{Kant's moral teleology}

2 In his exposition of the moral proof of God's existence in the Appendix to the Critique of the Teleological Power of Judgment, Kant distinguishes between two forms of teleology: physical teleology and moral teleology. While physical teleology is based plain-and-simply on a theoretical consideration of nature, moral teleology has a source in human beings considered as (practical-)rational beings. Insofar as we stand under the jurisdiction of the pure practical law of reason, we are compelled to relate ourselves as means "to ends and even a final end [Endzweck] that must be aimed at by us in the world" (Ak 5:4471). By prescribing "an end without a condition," the moral laws of reason "do exactly what the concept of a final end requires" (Ak 5:449): they furnish us with "an objective ground" for the nexus finalis which we can readily observed in nature - "an end which needs no other as the condition of its possibility" (Ak 5:434). By doing 
so, they put an end to the why questions which can be raised concerning the final causes of natural things.

The first thing to note about Kant's moral teleology is that it is not a branch of practical philosophy, but a teleology. It propounds not a way of handling (behandeln) natural things, but a way of judging (beurteilen) them. As Kant makes clear, moral teleology concerns "the reciprocal relation of the world to [the] moral end and the external possibility of its accomplishment" (Ak 5:447-48). The difference is further underscored by Kant when he draws attention to the distinctiveness of the "purposiveness of nature" from "practical purposiveness (of human art as well as of morals)" (Ak 5:181). Practical purposiveness, he cautions, derives from our capacity as rational beings to adopt or set ends for ourselves with regard to objects. An "end" in this sense "is an object of the choice (of a rational being), through whose representation choice is determined to an action to bring this object about" (Ak 6:381, translation modified. See also Ak 6:385). To distinguish it from the teleological concept of a natural end, we might call it a "practical end." As a teleology, moral teleology is concerned with natural rather than practical ends. It is no less a natural teleology than physical teleology is.

On Kant's view, we are already able to ascribe a "system of ends" to nature outside the context of moral teleology. By sheer theoretical consideration of nature, we are first able to judge some of its effects "immediately as a product of art" or "as material for the art of other possible natural beings." In the former case, we judge the effect as an internal end; in the latter case, we judge it as serving some external or relative end. If the effect is judged as serving an end of human beings, the means/end relation is one of usefulness (Nutzbarkeit); if it is judged as serving an end of other creatures, the relation is one of advantageousness (Zuträglichkeit) (see Ak 5:367). The concept of a natural end impels us to postulate "the idea of the whole of nature as a system of ends" (Ak 5:379). On the other hand, our rational capacity to form the concept of an end for ourselves allows us to "make a system of ends out of an aggregate of purposively formed things" (Ak 5:427). An end by means of which we are able to construct such a system of ends is called an "ultimate end" (letzte Zweck). While not every ultimate end qualifies as the final end, the final end certainly qualifies as the ultimate end. Kant is notably unsure of whether we are entitled by a sheer theoretical consideration of nature to ascribe relative ends - that is, relative ends taken to be natural ends - to natural things (and by implication, a system of ends to the whole of nature). ${ }^{2}$ As Paul Guyer puts it, "from a strictly naturalistic point of view, it is contingent whether we see the whole of nature or any subecology in it as a teleological system, and if we do so, it is arbitrary and indeterminate how we are able to see such a system as working - that is, what is end and what is the means in it." ${ }^{3}$ From within the context of moral teleology, however, Kant believes we are entitled to consider the relative ends we observe of natural things to be part of the natural scheme of things, and not artificial ends we arbitrarily read into them.

5 Additionally, though Kant is given to opposing relative purposiveness to the inner purposiveness that is characteristic of an internal end, he cites "a single external purposiveness that is connected with the inner purposiveness of organization and is such that, without raising the question of for what end such an organized being must exist, nevertheless serves in the external relation of a means to an end" (Ak 5:42). Here Kant has in mind the means/end relation that obtains between the organization of the sexes for the propagation of their species. Although the male and female are not 
"organized in a single body," they can nonetheless be said to constitute "an organizing whole" (Ak 5:425).

\section{Rethinking relative purposiveness}

6 At first glance, Kant's moral teleology seems to play no role in Fichte's ethics. To Kant, moral teleology is not a branch of practical philosophy and not concerned with practical purposiveness. Its possibility turns on the assumption that natural things have relative ends apart from the discretionary uses we freely make of them. Thus Fichte seems to rule out its possibility when he writes:

In nature, there is only an inner, and by no means a relative purposiveness. Relative purposiveness first arises only through the discretionary ends a free being is able to posit for itself in the objects of nature and is to some degree able to accomplish as well (SW IV: 128-294).

7 Unlike Kant then, Fichte flatly denies that the concept of relative purposiveness is applicable to natural things themselves apart from the discretionary uses we freely make of them. For him, relative purposiveness is an instance of practical purposiveness rather than an instance of the purposiveness of nature. This is especially evident in Section 15 (Subsection V), where he writes that the purposiveness - that is, relative purposiveness ${ }^{5}$ - of an object is nothing but "its usability [Brauchbarkeit] for certain arbitrary [beliebigen] ends that one might set for oneself with regard to this object" (SW IV: 171, translation modified). Accordingly, Hegel remarks of Fichte's teleology that it "represents everything which manifests itself naturally as existing for the sake of something else, namely to create a realm for free beings and to allow itself to be shattered so that free beings may rise above the ruins and fulfil their destiny." ${ }^{6}$ Nature assumes the guise of purposiveness only in the light of its practical relationship to us.

8 Nevertheless, I think we miss a great deal of what is interesting about Fichte's theory of purposiveness by approaching it in terms of Kant's concept of practical purposiveness (viz., functionality of objects for ends we set for ourselves). Throughout the SE, Fichte repeatedly draws attention to the difference of the practical ends we are compelled to posit by the necessity of reason from the practical ends we are free to posit by sheer play of the power of imagination. Unlike the former, the latter is firmly anchored in an original, determinate system of ends unified as means to the unconditioned "end of reason" (viz., "idea of the pure I"). According to Fichte, "the purposiveness of the sensible world is present for a human being only insofar as and only because he is able to set goals for himself, and he is able to do this only because his own reason provides him with an absolutely final goal (viz., morality)" (GA I/6: 413, translation modified ${ }^{7}$ ). ${ }^{8}$ In this light, not every end we imagine by wishful thinking counts for the "discretionary ends" that give rise to relative purposiveness. The relative ends of natural things are ends which are given only through the original, determinate system of ends in the following sense: they are either identifiable with the ends of the system or derivable from them.

9 First of all, Fichte recognizes a smaller class of relative ends than Kant. In the deduction of the human body (as an organized product of nature) in Section 8, Fichte ventures to revise the Kantian theory of organized systems on the basis of the Kantian insight that the parts of an organized system are characterized by their dependence on each other and on the whole. ${ }^{9}$ An important result of the revision is that the relations 
that obtain between the parts of an organized being come to be regarded as essentially the same as those that obtain between organized beings (as well as between organized beings and raw matter). The whole of nature becomes "a self-grounding whole, complete within itself; and precisely for this reason, it becomes an organized and organizing whole which possesses within itself and within its own immanent the ground of all the phenomena that occur within it" (SW V: 179-80). ${ }^{10}$ Recall that Kant cites a single instance of relative purposiveness that does not fit the bill - namely, the propagative end of the sexes' organization. By reconstruing nature as "an organized and organizing whole," Fichte in effect takes the single instance as a paradigm for explaining advantageousness. Granted that the kind of purposiveness Kant classifies under advantageousness is really inner rather than relative purposiveness, relative purposiveness amounts to nothing but what Kant means by usefulness.

10 Admittedly, when Fichte equates the purposiveness of an object with its usability for our arbitrary ends, he seems to think that natural things have no relative ends apart from the discretionary uses we freely make of them. But this interpretation cannot be sustained upon a careful reading of Section 17 (Subsection IV) of the SE. Here I will cite the crucial passage in two parts. The first part speaks to what the "final end" (Endzweck) of a natural thing is:

a determinate object is posited only in consequence of some determinate limitation of a drive; it is posited in order to explain this limitation. If the drive itself, qua drive, is posited (as a longing or desiring) and is referred to the object, then one obtains what the I wants to bring about in the object, what the I might use the object for; i.e., one obtains the thing's original, determinate end - which is by no means the same thing as an end one has arbitrarily [willkürlich] posited for the object. (SW IV: 210, translation modified)

11 The drive in question is the "original drive" (Urtrieb). Each natural thing is posited by the I in the first place in order to explain the limitation of the original drive. On this basis, we are entitled to regard the end obtained by the I when it refers the drive to the natural thing as "the thing's original, determinate end" - what the thing is meant as it were to be used for. This so-called "final end" of a natural thing must not be confounded with the unconditioned final end of the whole of nature - the self-sufficiency of reason or idea of the pure I.

The second part of the passage speaks to how the final end of a natural thing is related to its usability as such:

It follows from the preceding remark, however, that every arbitrary [willkürliche] end is at the same time an original one; or, to put it more clearly, it follows that I am at least unable to achieve any end that is not demanded by an original drive. But it is quite possible for me to apprehend only a part of my original drive when it aims at an object, and in that case, I grasp only a portion of the thing's purposiveness. (SW IV: 210)

Kant himself suggests such a relationship of an arbitrary to an original end when he remarks that an "action which is morally absolutely necessary can be regarded physically as entirely contingent (i.e., what necessarily ought to happen often does not)" (Ak 5:403n, translation modified). It turns on the thought that if an action or end $X$ ought to be, then $X$ can but need not be, and if $X$ need not be, then $\sim X$ as well as $X$ can be. In this way, no final end of a thing is given as a possible end except together with a cluster of other possible ends. Fichte's contention then is that the entire cluster of the thing's possible ends exhausts its usability. ${ }^{11}$ 


\section{The significance of moral teleology}

14 Even as Fichte undercuts Kant's moral teleology by denying that natural things have relative ends apart from the discretionary uses we freely make of them, he reintroduces it at the higher level as part of a theory of practical purposiveness. By this theory, not every end we can think up or will by a "sheer empty willing" (SW IV: 73) is an end we can actually will (wollen) and realize (wirken) in the world of sense. Although both classes of ends are marked by their "thinkability" (Denkbarkeit), the latter class of ends is distinguished from the former by their "perceptibility" (Wahnehmbarkeit) or "capacity to be sensed" (Empfindbarkeit). To be sure, we exercise our power of choice by freely choosing from among a manifold of possible ends. In doing so, however, we choose only from among possible ends which are given through the final ends of natural things as parts of an original, determinate system of ends.

15 At the outset, I have suggested that Fichte's approach to the deduction of the moral law's applicability in the SE is prompted by Kant's moral teleology. This is suggested in a note to Collegium über die Moral, where he identifies the "purposiveness of nature" as key to the "matter [Materie] of the moral law" (see GA IV/1:41). To appreciate the latter's significance, we need to first elucidate the problem he seeks to solve by the deduction, and how the final ends of natural things contribute to solving it.

16 In Kantian ethics, one typically assumes that the applicability of the moral law concerns its practical employment as a discursive criterion for moral actions. But in his discussion of the object of pure practical reason in Chapter Two of the Analytic of Practical Reason, Kant in fact raises two distinct questions: the first which we might call the "question of schematism" is the transcendental one concerning how the "supersensible idea of the morally good" can be "presented [dargestellt] in concreto in a sensible intuition" (Ak 5:68); the second which we might call the "question of appraisal" is the practical one concerning how actions in conformity with duty can be told apart from actions which are not (Ak 5:69). According to Kant, the question of schematism is unanswerable because we simply have no a priori intuition by means of which to mediate a supersensible idea by a sensible intuition. Notwithstanding, an adequate answer to the question of appraisal can be given in terms of the typic of a universal law of nature. By applying the mere typic of the law, we are able to judge whether an action is our moral duty without having to have recourse to the presentation of the idea of the good in concreto in sensible intuitions.

17 In response, Fichte insists that the question of schematism cannot be avoided because we would be at a loss in applying the law if we did not know where in the world of sense the law is to be applied. The applicability of the law presupposes the availability of answers to the questions:

To which domain of the sensible world do the demands made upon me by the moral law refer? How am I supposed to recognize this domain in general, and do so systematically? How am I even supposed to recognize how I ought to work upon each determinate object within this domain in accordance with the moral law how I ought to work upon precisely this A and this B, etc.? (SW IV: 66, translation modified)

18 The fact that we are not at a loss in applying the law only goes to show that the typic is already "actually operative" (SW I: 506) as a constitutive principle in our everyday life. ${ }^{12}$ 
A deduction of the moral law's applicability is only left with the task of showing that (and how) this is so. In all fairness, we can say that the deduction addresses not so much the question of appraisal as the question of schematism. ${ }^{13}$

Agreeing with Kant that we have no a priori intuition by means of which to mediate the idea of the good by a sensible intuition, Fichte sees an alternative approach to the question of schematism in Kant's moral teleology. Kant suggests it when he remarks that moral teleology

is just as necessarily connected with the nomothetic of freedom on the one hand and that of nature on the other as civil legislation is connected with the question of where the executive power should be sought, and with the general question of how reason is to provide a principle of reality of a certain lawful order of things that is possible only in accordance with ideas (Ak 5:448, emphases added).

But alas, the promise (if there is one) turns out to be empty! For Kant, the moral law can be universally enforced (allgemeingeltend) as a cosmic principle only by means of a morally impeccable and supremely powerful and intelligent Person. Since we have no systemic epistemic access to the workings of such a divine Person, moral teleology leaves us practically clueless as to where the executive power of the nomothetic of freedom is to be sought. Thus Kant's moral teleology turns out to have no relevance for mediating the idea of the good by sensible intuitions.

21 Notwithstanding, Fichte is summoned by Kant's suggestive remark to explore the possibility of accomplishing the task by means of the concept of the original, determinate end of a natural thing. In the hope of doing so, he advances the controversial thesis that the law is actually operative in ordinary consciousness as "a theoretical principle for the determination of the world" (SW IV: 68). As is clear from our examination of Section 17 (Subsection 14), we acquire cognition of the final ends of natural things when the I refers the original drive to the things. Now the original drive is none other than the concept of morality (or freedom) considered as a transcendental law (viz., law of reason as such). Inasmuch as the I refers it to natural things, the concept comes into play as a theoretical principle. From Section 15, we know that the exact power of cognition involved in the process is the reflecting power of judgment. The claim then is that through our immediate feeling of the harmony/disharmony of the varying reflecting judgments we pass upon natural things with the drive, we are able to settle upon a stable cognition of what each thing is meant to be used for (viz., how it is meant to be handled). In this way, the normative authority of what each thing is meant to be used for is immediately felt. Of course, this does not mean that we cannot choose to act contrary to it. But it does mean that we cannot choose to act contrary to it without getting into trouble with ourselves and with others. Although Fichte does not set out to give an exhaustive list of these "original determinations" (Urbestimmungen), it is safe to say that he has in mind at least (i) the contingency of our world, (ii) the articulation of our body, and (iii) the rationality of some other beings. Inasmuch as we are conscious of our world as contingent, we cognize that natural things are meant to be used solely as tools (Werkzeugen) for advancing our goals. As contingency is essentially modifiability, consciousness of our world as contingent amounts to consciousness of an invitation to act upon it. Also, inasmuch as we are conscious of our body as articulated, we cognize that our body is meant to be used in the same way. We misuse it by using it for the sole end of sensual enjoyment. In other words, our body as well as the whole of nature have us for their 
final ends. On the other hand, inasmuch as we are conscious of some other beings as rational, we cognize them not only as not being meant to be used solely as tools for advancing our goals, but as being meant not to be used in this way. When the I refers the original drive to a "product of artifice" (including the body of another rational being), it finds the drive to be limited in a "particular and characteristic" way: its very drive to act "is repulsed" (SW IV: 225).

By a deduction of the moral law's applicability, the final ends of our world, our body and other rational beings are shown to be grounded in a transcendental law (or, what is the same, the original drive). Moreover, their normative authority derives from the fact that the law in question is the moral law. In this light, there is no tautology in stating the demand of the moral law as follows: Handle each natural thing in accordance with (your cognition of) what it is meant to be used for. In Fichte's eyes, this way of fleshing out the law's demand marks an improvement over Kant's formulas primarily because it simultaneously specifies the domain of the world of sense where the demand is to be met. As he puts it, it determines not only "the idea of what we ought to do," but also "the substrate in which we ought to approximate the realization of this idea" (SW IV: 70).

\section{NOTES}

1. Ak is short for Immanuel Kant Schriften. Ausgabe der königlich preussischen Akademie der Wissenschaften (Berlin: Walter de Gryuter, 1902-.

2. "We have said that the external purposiveness of natural things offers no sufficient justification for using them at the same time as ends of nature, as grounds for the explanation of their existence, and using their contingently purposive effects, in the idea, as grounds for their existence in accordance with the principle of final causes" (Ak 5:377. See also Ak 5:367-69).

3. Paul Guyer, "Kant's Principles of Reflecting Judgment," Kant's Critique of the Power of Judgment: Critical Essays, ed. Paul Guyer (New York: Rowman \& Littlefield, 2003), 52.

4. SW is short for Fichtes Sammtliche Werke, ed. Immanuel H. Fichte (Berlin: Walter de Gruyter, 1970).

5. Fichte tends to use the term purposiveness exclusively to mean relative purposiveness, and does not regard inner purposiveness as purposiveness proper speaking.

6. Georg W. F. Hegel, "Glauben und Wissen," Erste Druckschriften, ed. Georg Lasson (Leipzig: Meiner, 1928), 334-35, translation is mine. Likewise, Arnold Farr notes that the reflecting power of judgment by which we think of nature as purposive "tells us nothing about nature and does not affect nature but only affects the human subject." Farr, "Reflecting Judgment and the Boundaries of Finite Human Knowledge: The Path toward Fichte's 1794/95 Wissenschaftslehre," New Essays in Fichte's Foundation of the Entire Doctrine of Scientific Knowledge, ed. Dan Breazeale and Tom Rockmore (New York: Humanity Books, 2001), 107.

7. GA is short for J. G. Fichte - Gesammtausgabe, ed. Reinhard Lauth and Hans Gliwitzky (StuttgartBad Cannstatt: Frommann, 1962-).

8. Daniel Breazeale's separate treatment of our practical dominion over nature and our consciousness of nature's final end is somewhat misleading as it suggests that the former is possible without the latter. See Breazeale, "Against Nature? On the Status and Meaning of the Natural World in Fichte's Early Wissenschaftslehre," Philosophia Osaka, No. 9, Mar 2014: 29-34. As I 
understand Fichte, our cultural and technical mastery of natural things has to presuppose some consciousness, however obscure, of their final ends.

9. The insight is concisely stated at two points in the Foundation of Natural Right (FNR) (see SW III: 203, 208-09).

10. See also SW IV: 124.

11. One cannot help but marvel at the consistency with the critique of Rousseau in the fifth lecture of Some Lectures of the Vocation of a Scholar. There Fichte agrees with Rousseau that culture entails the development of sensibility and its needs, and makes possible vice and corruption. But it also makes possible virtue and reason. By abolishing culture, we eradicate vice and corruption. But we thereby also eradicate virtue and reason (see SW VI: 340-41). Likewise, Fichte shows here how the possibility of virtue and reason $(X)$ must give rise to the possibility of vice and corruption $(\sim X)$.

12. The same point is made in Fichte's critique in the FNR of the Kantian formula of the categorical imperative "Act so that the maxim of your will can be the principle of a universal legislation" (see SW III: 80-81). Barbara Herman seems to have reached a similar conclusion about what she argues that the categorical imperative (CI) "cannot be an effective practical principle of judgment unless agents have some moral understanding of their actions before they use the $\mathrm{CI}$ procedure." Barbara Herman, The Practice of Moral Judgment, Cambridge, Massachusetts: Harvard University Press, 1993, 77.

13. Commentators are generally agreed that one looks in vain for a discursive criterion for moral actions in the SE. See Daniel Breazeale, "In Defense of Fichte's Account of Ethical Deliberation," Archives für Geschichte der Philosophie (Berlin: Walter de Gruyter, 2012), 199, and Allen Wood, Fichte's Ethical Thought (Cambridge: Cambridge University Press, 2016), 137-38, 149.

\section{ABSTRACTS}

Fichte's System of Ethics (SE) investigates the moral law's function as a cosmic principle with the hope of delivering a deduction of its applicability in the world of sense. In the work, Fichte harnesses the concept of the original, determinate end of a natural thing as a means of mediating the Kantian "supersensible idea of the morally good" by sensible intuitions. In doing so, he is inspired above all by Kant's moral teleology. This concerns, not the metaphysics of morals as practical philosophy but moral teleology (as a prelude to moral theology). By a deduction of the moral law's applicability, the final ends of our world, our body and other rational beings are shown to be grounded in a transcendental law (or, what is the same, the original drive)..

\section{INDEX}

Keywords: Kant, Fichte, System of Ethics, moral law, moral teleology 
AUTHOR

KIENHOW GOH

Suwon, South Korea 